'Hepatocyte fatty acid desaturation and polyunsaturated fatty acid composition of liver in salmonids: Effects of dietary vegetable oil' by D. R. Tocher, J. G. Bell, P. MacGlaughlin, F. McGhee, and J. R. Dick. Comparative Biochemistry and Physiology Part B: Biochemistry and Molecular Biology, Volume 130, Issue 2, September 2001, pp. 257 - 270.

Published in Comparative Biochemistry and Physiology Part B: Biochemistry and Molecular Biology by Elsevier. Comparative Biochemistry and Physiology Part B: Biochemistry and Molecular Biology, Volume 130, I ssue 2, September 2001, pp. $257-270$.

This is the peer reviewed version of this article.

NOTICE: this is the author's version of a work that was accepted for publication in Comparative Biochemistry and Physiology Part B: Biochemistry and Molecular Biology. Changes resulting from the publishing process, such as peer review, editing, corrections, structural formatting, and other quality control mechanisms may not be reflected in this document. Changes may have been made to this work since it was submitted for publication. A definitive version was subsequently published in Comparative Biochemistry and Physiology Part B: Biochemistry and Molecular Biology, VOL 130, ISSUE 2, (September 2001). DOI 10.1016/S1096-4959(01)00429-8. 


\title{
Hepatocyte fatty acid desaturation and polyunsaturated fatty acid composition of liver in salmonids: Effects of dietary vegetable oil.
}

\author{
D. R. Tocher, * J. G. Bell, MacGlaughlin, P., , F. McGhee, J.R. Dick \\ Institute of Aquaculture, University of Stirling, Stirling FK9 4LA, Scotland \\ ${ }^{I}$ Fisheries Research Service, Marine Research Unit, Aultbea, Wester Ross, Scotland.
}

* Corresponding author. Dr. Douglas R. Tocher, Institute of Aquaculture, University of Stirling, Stirling FK9 4LA, Scotland. Tel.: +44-1786-467996; Fax.: +44-1786-472133.

E-mail address: d.r.tocher@stir.ac.uk (D.R.Tocher)

\begin{abstract}
Abbreviations: AA, arachidonic acid; BHT, butylated hydroxytoluene; DHA, docosahexaenoic acid; EFA, essential fatty acid; EPA, eicosapentaenoic acid; FAF-BSA, fatty acid free bovine serum albumin; FO, fish oil; HBSS, Hanks balanced salt solution; HUFA, highly unsaturated fatty acids acids (carbon chain length $\geq \mathrm{C}_{20}$ with $\geq 3$ double bonds); PL, polar lipid; PUFA, polyunsaturated fatty acids; VO, vegetable oil; TLC, thin-layer chromatography.
\end{abstract}




\section{Abstract}

The desaturation and elongation of $\left[1{ }^{14} \mathrm{C}\right] 18: 3 \mathrm{n}-3$ was investigated in hepatocytes from different populations and three different species of salmonids indigenous to Scotland, brown trout, Atlantic salmon and Arctic charr. Two groups of fish were sampled, before and after they were fed two experimental diets, a control diet containing fish oil and a diet containing vegetable oil (a 1:1 blend of linseed oil and rapeseed oil) for 12 weeks. At each sampling time, fatty acyl desaturation and elongation activity was determined in isolated hepatocytes and samples of liver were also collected for lipid compositional analysis. At the initiation of the dietary trial, the liver polar lipid fatty acid compositions of salmon and brown trout were very similar to each other, and the two charr populations were similar to each other having lower total n-3 polyunsaturated fatty acids (PUFA) and 22:6n-3, but higher 20:5n-3 than the other salmonids. Initially, hepatocyte desaturation activity varied with the highest activity in brown trout followed by salmon then charr. Production of 20:5n-3 was particularly high in brown trout. Desaturation of $\left[1-{ }^{14} \mathrm{C}\right] 18: 3 n-3$ was significantly greater in all fish fed the diet containing vegetable oil compared to fish fed the diet containing fish oil. The increase in activity was less in brown trout compared to the other groups of fish. Feeding the vegetable oil diet increased the levels of 18:2n-6, 20:3n-6, total n-6PUFA, 18:3n-3, 18:4n-3, 20:3n-3 and 20:4n-3, and decreased 22:6n-3 and the n-3/n-6 ratio in salmon and brown trout. By contrast, in charr fed the vegetable oil diet, there was no increase in 18:3n-3, 18:4n-3, 20:3n-3 or 20:4n-3 in liver polar lipid and the level of 22:6n-3 was not decreased. In addition, there was only a modest increase in the levels of 18:2n-6 and total n-6PUFA and so the n-3/n-6 ratio was only slightly decreased. The percentage of 20:4n-6, which was not increased in salmon and brown trout fed vegetable oil, was increased in charr fed the vegetable oil diet. Overall, the results indicated that there were significant differences in liver PUFA metabolism between Arctic charr and the other salmonids that could have important consequences, both physiologically and in their ability to be successfully cultured on diets containing vegetable oils.

Running title: PUFA composition and desaturation in salmonids.

Keywords: Salmonids, salmon, charr, trout, hepatocytes, PUFA, desaturation, composition. 


\section{Introduction}

Most animals, including mammals and fish, are unable to biosynthesise the polyunsaturated fatty acids (PUFA), linoleate (18:2n-6) and linolenate (18:3n-3) de novo and so they are termed essential fatty acids (EFA) (Holman, 1986). However, the precise EFA requirements of fish varies both quantitatively and qualitatively between different species (Watanabe, 1982; Kanazawa, 1985; Sargent et al., 1995,1999). Fish species displaying a so-called "freshwater" pattern are able to convert the $\mathrm{C}_{18}$ EFA, 18:3n-3 and 18:2n-6, to the longer chain, more unsaturated and physiologically important highly unsaturated fatty acids (HUFA), eicosapentaenoic acid (20:5n-3; EPA), docosahexaenoic acid (22:6n-3; DHA) and arachidonic acid (20:4n-6; AA), via a series of fatty acid desaturase and elongase enzymes, and so only require the $\mathrm{C}_{18}$ PUFA (Henderson and Tocher, 1987; Sargent et al., 1989,1995). In contrast, fish species displaying a typical "marine" pattern cannot perform these conversions at an appreciable rate and so require a dietary source of the essential HUFA (Sargent et al., 1989,1995). This paradigm was based on data from relatively few species stemming mainly from original work on one freshwater species, rainbow trout (Oncorhynchus mykiss), and one marine species, turbot (Scophthalmus maximus) (Owen et al., 1975). However, in recent years, other fish species have been studied which indicate that this paradigm is generally correct although it has been speculated that the "marine" pattern may actually be a pattern associated with adaptation to a carnivorous lifestyle (Mourente and Tocher, 1993,1994; Sargent et al., 1995). The hypothesis being that consumption of a carnivorous/piscivorous diet, naturally rich in HUFA, results in an evolutionary down-regulation of the desaturase and/or elongase enzyme activities required for the conversion of $\mathrm{C}_{18}$ PUFA to HUFA (Sargent et al., 1995). Perhaps supporting this view, the carnivorous freshwater fish, the pike (Esox lucius), displayed only very limited ability to convert 18:3n-3 to EPA or 18:2n-6 to AA (Henderson et al., 1995; Buzzi et al., 1997). There is currently much interest in fatty acid desaturation pathways in fish as there is an urgent need to replace the $\mathrm{C}_{20 / 22}$ HUFA-rich fish oils, derived from non-sustainable marine fisheries, with vegetable oils, rich in $\mathrm{C}_{18}$ PUFA, in the diets of aquacultured fish species (Sargent and Tacon, 1999).

In addition to possible evolutionary adaptations to dietary lifestyles, diet is also known to directly affect desaturase enzyme activities in mammals (Brenner, 1981). Recently, we showed that the hepatic desaturation of 18:3n-3 and 18:2n-6 was significantly greater in Atlantic salmon parr (in freshwater) and post-smolts (in seawater) fed diets containing vegetable oils compared to fish fed diets containing fish oils (Bell et al., 1997; Tocher et al., 1997,2000). In the studies on freshwater parr, the vegetable oil 
diets contained rapeseed oil, linseed oil, or a blend of the two, formulated to provide high levels of 18:2n-6 and 18:3n-3 and only low levels of $\mathrm{C}_{20}$ and $\mathrm{C}_{22}$ HUFA, a composition that more closely mimics the fatty acid composition of freshwater aquatic insects that make up the diet of wild salmon parr (Bell et al., 1994). Desaturase activities in salmon, previously fed vegetable oil during the parr stage were reduced to very low levels upon feeding a diet containing fish oil simultaneous with transferring the smolts to seawater (Bell et al., 1997; Tocher et al., 2000). Increased hepatic fatty acid desaturase activities were also induced in rainbow trout fed a diet containing olive oil compared to a diet containing fish oil (Buzzi et al., 1996). The conversion of intraperitoneally injected ${ }^{14} \mathrm{C}-$ labelled 18:2n6 and 18:3n-3 to HUFA was increased in Arctic charr (Salvelinus alpinus) fed diets containing only $\mathrm{C}_{18}$ PUFA compared to commercial diets containing fish oil (Olsen and Ringo, 1992). Moreover, comparison of these studies on various salmonids showed that the extent of their ability to desaturate $\mathrm{C}_{18}$ PUFA appeared to vary between the species (Olsen and Ringo, 1992; Buzzi et al., 1996; Bell et al., 1997; Tocher et al., 2000). Furthermore, in the course of work investigating smoltification in different populations of Atlantic salmon (wild, Scottish farmed stock and Norwegian farmed stock), we have also observed variation in hepatic fatty acid desaturation/elongation activities between the different populations (Tocher, D.R. and Bell, J.G., unpublished data). However, many differences between the studies including, in particular, dietary formulations/compositions and assay methodologies make direct comparison difficult.

This prompted us to further investigate differences in fatty acid desaturation between salmonid species and in distinct populations within species that may have different dietary habits. In the present study we investigated the desaturation and elongation of $\left[1-{ }^{14} \mathrm{C}\right] 18: 3 \mathrm{n}-3$ in hepatocytes from three different species of salmonids indigenous to Scotland, brown trout, wild Atlantic salmon and Arctic charr. We also investigated differences between different populations of the same species by looking at charr from two genetically and geographically distinct populations with characteristic and different feeding habits. In addition, progeny of a cross between the wild Scottish Atlantic salmon stock used here and a land-locked Canadian Atlantic salmon were investigated. Fish were sampled initially after they had been maintained for up to one year and so were fully acclimated to the experimental systems. Fish from each species and group were then fed two diets, a control diet containing fish oil and a diet containing vegetable oil (a 1:1 blend of linseed oil and rapeseed oil) for 12 weeks. At each sampling time, fatty acyl desaturation and elongation activity was determined in isolated hepatocytes and samples of liver were also collected for lipid compositional analysis. 


\section{Materials and methods}

\subsection{Animals and diets}

Fish from different wild populations of three species of indigenous salmonids in Scotland were investigated; Atlantic salmon (Salmo salar) (from the River Don, Aberdeenshire, Scotland) (Ssalmon), brown trout (Salmo trutta) (from the River Ewe, Wester Ross, Scotland), Arctic charr (Salvelinus alpinus) from two different populations from two locations; firstly, Loch Rannoch, Perthshire, which is deep and contains two populations of charr, the one used was a reportedly demersal, piscivorous population (R-charr); the other population of Arctic charr were from Loch Coulin, Wester Ross, a shallow loch and the fish used are from a population that is reputedly planktonivorous (C-charr); and a final group of salmon that were F1 crosses of a Canadian land-locked Atlantic salmon population (Bristol Cove River, Newfoundland) with wild River Don fish (F1 salmon). River Don salmon were grown from eggs and milt stripped from fish collected in traps on the river and transported to the hatchery in Aultbea as green eggs. The other salmonids were out bred one year i.e. they were progeny of eggs and milt from wild-caught fish held in the aquaria at SOAFD, Aultbea and were ongrown juveniles of approximately 1 year of age. After sampling fish for the initial sample, six fish from each population were placed in each of four tanks after applying an identification dye-mark. The one metre fibreglass tanks contained $500 \mathrm{~L}$ of non-recirculated freshwater supplied at a rate of 10 $1 /$ min. The initial sampling was performed in the middle of June, immediately before the fish were transferred to the experimental diets. Final sampling was performed 12 weeks later in mid September. Before the start of the experiment all fish were on natural photoperiod but were switched to $12 \mathrm{~h}$ light and $12 \mathrm{~h}$ dark two weeks before the trial was initiated and remained on this controlled regime throughout the trial. There was no evidence of smoltification during the experimental period. The diets were fed to satiation, to duplicate tanks of fish, using automatic feeders. Experimental diets were prepared by Trouw Aquaculture (Renfrew, Scotland). The diets contained 54\% protein and 19\% lipid and their formulation is shown in Table 1. The fatty acid compositions of the diets are shown in

Table 2. All diets were formulated to satisfy the nutritional requirements of salmonid fish (U.S. National Research Council, 1993). 


\subsection{Lipid extraction and fatty acid analysis}

Intact livers were dissected from three fish per group and dietary treatment, at each sampling point, and immediately frozen in liquid nitrogen. Total lipid was extracted from liver and diet samples by the method of Folch et al. (1957). For diets, fatty acid methyl esters (FAME) were prepared from total lipid by acid-catalysed transesterification using $2 \mathrm{ml}$ of $1 \% \mathrm{H}_{2} \mathrm{SO}_{4}$ in methanol plus $1 \mathrm{ml}$ toluene as described by Christie (1982). For liver samples, total polar lipid (PL) was prepared by separating neutral lipids from PL by thin-layer chromatography (TLC) using hexane/diethylether/acetic acid (80:20:2, by vol.) as developing solvent. The PL retained on the origin was scraped and subjected to acid-catalysed transesterification, directly on the silica, as above. FAME were separated and quantified by gas-liquid chromatography (Carlo Erba Vega 8160, Fisons Ltd., Crawley, U.K.) using a 30m x 0.32 mm capillary column (CP wax 52CB; Chrompak Ltd., London, U.K). Hydrogen was used as carrier gas and temperature programming was from $50^{\circ} \mathrm{C}$ to $150^{\circ} \mathrm{C}$ at $40^{\circ} \mathrm{C} / \mathrm{min}$ and then to $230^{\circ} \mathrm{C}$ at $2.5^{\circ} \mathrm{C} / \mathrm{min}$. Individual methyl esters were identified by comparison to known standards and by reference to published data (Ackman, 1980).

\subsection{Preparation of isolated hepatocytes}

Fish were killed by a blow to the head and the livers dissected immediately. The gall bladder was removed carefully from the liver and the main blood vessels removed. The liver was perfused via the hepatic vein with solution A (calcium and magnesium-free Hanks balanced salt solution (HBSS) +10 mM HEPES + $1 \mathrm{mM}$ EDTA), using a syringe fitted with a $23 \mathrm{~g}$ needle, to clear blood from the tissue. The liver was chopped finely with scissors and incubated with $20 \mathrm{ml}$ of solution A containing $0.1 \%$ (w/v) collagenase in a $25 \mathrm{ml}$ "Reacti-flask" in a shaking water bath at $20^{\circ} \mathrm{C}$ for $45 \mathrm{~min}$. The digested liver was filtered through $100 \mu \mathrm{m}$ nylon gauze and the cells collected by centrifugation at $300 \mathrm{x} \mathrm{g}$ for 2 min. The cell pellet was washed with $20 \mathrm{ml}$ of solution A containing $1 \% \mathrm{w} / \mathrm{v}$ fatty acid-free bovine serum albumin (FAF-BSA) and re-centrifuged. The hepatocytes were resuspended in $10 \mathrm{ml}$ of Medium 199 containing $10 \mathrm{mM}$ HEPES, $2 \mathrm{mM}$ glutamine, $100 \mathrm{U} / \mathrm{ml}$ penicillin and $0.1 \mathrm{mg} / \mathrm{ml}$ streptomycin. One hundred $\mu \mathrm{l}$ of cell suspension was mixed with $400 \mu \mathrm{l}$ of Trypan Blue and hepatocytes were counted and their viability assessed using a haemocytometer. One hundred $\mu l$ of the cell suspension was retained for protein determination. 


\subsection{Assay of hepatocyte fatty acyl desaturation/elongation activities}

Five $\mathrm{ml}$ of each hepatocyte suspension were dispensed into two $25 \mathrm{~cm}^{2}$ tissue culture flasks. Hepatocytes were incubated with $0.25 \mu \mathrm{Ci}$ of $\left[1-{ }^{14} \mathrm{C}\right] 18: 3 \mathrm{n}-3$, added as a complex with FAF-BSA in phosphate buffered saline prepared as described previously (Ghioni et al., 1997). After addition of isotope the flasks were incubated at $20{ }^{\circ} \mathrm{C}$ for $2 \mathrm{~h}$. After incubation, the cell layer was dislodged by gentle rocking, the cell suspension transferred to glass conical test tubes and the flasks washed with 1 $\mathrm{ml}$ of ice-cold HBSS containing 1\% FAF-BSA. The cell suspensions were centrifuged at $300 \mathrm{~g}$ for 2 min, the supernatant discarded and the cell pellets washed with $5 \mathrm{ml}$ of ice-cold HBSS/FAF-BSA. The supernatant was discarded and the tubes placed upside down on paper towels to blot for $15 \mathrm{sec}$ before extraction of total lipid using ice-cold chloroform/methanol $(2: 1, \mathrm{v} / \mathrm{v})$ containing $0.01 \%(\mathrm{w} / \mathrm{v})$ butylated hydroxy toluene (BHT) essentially as described by Folch et al. (1957) and as described in detail previously (Tocher et al., 1988).

Total lipid was transmethylated and FAME prepared as described above. The methyl esters were redissolved in $100 \mu \mathrm{l}$ hexane containing $0.01 \%$ BHT and applied as $2.5 \mathrm{~cm}$ streaks to TLC plates impregnated by spraying with $2 \mathrm{~g}$ silver nitrate in $20 \mathrm{ml}$ acetonitrile and pre-activated at $110{ }^{\circ} \mathrm{C}$ for 30 min. Plates were fully developed in toluene/acetonitrile (95:5, v/v) (Wilson and Sargent, 1992). Autoradiography was performed with Kodak MR2 film for 6 days at room temperature. Silica corresponding to individual PUFA was scraped into scintillation mini-vials containing $2.5 \mathrm{ml}$ of scintillation fluid (Ecoscint A, National Diagnostics, Atlanta, Georgia) and radioactivity determined in a TRI-CARB 2000CA scintillation counter (United Technologies Packard, U.K.). Results were corrected for counting efficiency and quenching of ${ }^{14} \mathrm{C}$ under exactly these conditions.

\subsection{Protein determination}

Protein concentration in isolated hepatocyte suspensions was determined according to the method of Lowry et al. (1951) after incubation with $0.25 \mathrm{ml}$ of $0.25 \%(\mathrm{w} / \mathrm{v}) \mathrm{SDS} / 1 \mathrm{M} \mathrm{NaOH}$ for $45 \mathrm{~min}$ at $60^{\circ} \mathrm{C}$. 


\subsection{Materials}

$\left[1-{ }^{14} \mathrm{C}\right] 18: 3 \mathrm{n}-3$ (50-55 mCi/mmol) was obtained from NEN (DuPont (U.K.) Ltd., Stevenage, U.K.). HBSS, Medium 199, HEPES buffer, glutamine, penicillin, streptomycin, collagenase (type IV), FAFBSA, BHT and silver nitrate were obtained from Sigma Chemical Co. (Poole, U.K.). Thin-layer chromatography (TLC) plates, precoated with silica gel 60 (without fluorescent indicator) were obtained from Merck (Darmstadt, Germany). All solvents were HPLC grade and were obtained from Fisher Scientific UK, Loughborough, England.

\subsection{Statistical analysis}

All the data are presented as means $\pm S D(n=3)$ unless otherwise stated. The significance of effects on liver fatty acid compositions and hepatocyte fatty acid desaturation due to species/population were analysed by one-way ANOVA with, where appropriate, differences between means determined by Tukey's post-test. Differences due to species/population and diet and their interaction were determined by two-way analysis of variance (ANOVA). Percentage data and data which were identified as nonhomogeneous (Bartlett's test) were subjected to either arcsine, square root or log transformation before analysis. Differences were regarded as significant when $\mathrm{P}<0.05$ (Zar, 1984).

\section{Results}

\subsection{Liver lipid contents}

The total lipid content of liver from the C-charr at the beginning of the dietary trial was slightly lower than the other salmonids liver lipid contents but only significantly in the case of F1-salmon whereas it was slightly higher than the other salmonids after feeding the fish oil diet (Table 3). However, two-way ANOVA showed that the overall effects of species were not significant. The effects of diet were significant but were not the same for all species as indicated by the significant interaction. Thus, whereas the lipid content of livers from S-salmon, F1-salmon and brown trout were lower after feeding the fish oil diet compared to both initial fish and fish fed the vegetable oil diet, this was not the case with either group of charr (Table 3). 


\subsection{Liver fatty acid compositions at the initiation of the trial.}

The fatty acid compositions of polar lipid from liver are shown in Table 4. The S-salmon, F1salmon and brown trout compositions were very similar to each other and the two charr populations were similar to each other. However, both charr groups were characterised by having slightly lower levels of total PUFA due to a lower level of total n-3PUFA and this was almost entirely due to a decreased proportion of DHA whereas EPA was higher in the both charr groups than the other salmonids (Table 4). The lower percentage of PUFA in the charr was accompanied by increased percentages of monoenes, particularly 18:1n-9.

\subsection{Hepatocyte fatty acid desaturation/elongation activities at the initiation of the trial.}

The hepatocyte desaturation/elongation activity, determined immediately before the initiation of the dietary trial and using $\left[1-{ }^{14} \mathrm{C}\right] 18: 3 \mathrm{n}-3$ as substrate, displayed a significant variation between the species (Fig. 1). The brown trout displayed the highest overall desaturation activity, significantly higher than all the other species and up to 3-fold higher than the lowest activity observed in R-charr. The two salmon groups were not significantly different to each other but overall hepatocyte fatty acid desaturation was significantly lower in the R-charr compared to the C-charr (Fig.1). Production of 20:4n-3, EPA, 22:5n-3 and DHA from $\left[1-{ }^{14} \mathrm{C}\right] 18: 3 n-3$ was highest in the brown trout whereas the high overall level of desaturation/elongation of $\left[1-{ }^{14} \mathrm{C}\right] 18: 3 \mathrm{n}-3$ in S-salmon was due mainly to a high level of desaturation to $18: 4$ n-3 (Fig.2).

\subsection{Effects of diet on liver fatty acid compositions}

There were major differences between the species in the dietary effects observed in liver polar lipid fatty acid compositions (Tables 5 and 6). This was confirmed by the results of two-way ANOVA of selected fatty acids which showed that liver polar lipid fatty acid composition was not only significantly affected by species and diet but, in addition, there was significant interactions between these variables indicating that the effects of diet were highly dependent upon the species (Table 7). Thus, feeding the vegetable oil diet increased the levels of 18:2n-6, 20:3n-6 and total n-6PUFA, and $18: 3 n-3,18: 4 n-3,20: 3 n-3$ and $20: 4 n-3$ in the two salmon groups and brown trout. This was accompanied in these fish by decreased proportions of saturated fatty acids and, especially, DHA. The 
n-3/n-6 ratio was reduced by up to 2.5 -fold in these groups. In contrast, in both charr groups fed the VO diet there was no increase in 18:3n-3, 18:4n-3, 20:3n-3 or 20:4n-3 in liver polar lipid and the level of DHA was not decreased (Tables 5 and 6). Similarly, there was only a very modest increase in the levels of 18:2n-6 and total n-6PUFA in the charr fed the VO diet and the n-3/n-6 ratio was only slightly decreased. The percentage of AA, which was not increased in the salmon groups and brown trout fed vegetable oil, was increased in both charr groups fed the VO diet (Tables 5 and 6).

\subsection{Effects of diet on hepatocyte fatty acid desaturation/elongation activities.}

The desaturation/ elongation of $\left[1-{ }^{14} \mathrm{C}\right] 18: 3 \mathrm{n}-3$ in isolated hepatocytes was significantly increased in all species and groups of fish by feeding the VO diet (Fig.3). With brown trout, S-salmon and Rcharr there was a two-fold increase in the activity of the fatty acid desaturation/elongation pathway upon feeding the VO diet, whereas the increase was approximately three-fold for C-charr and the F1salmon (Fig.3). An apparent temporal effect was also observed in that the activities of the hepatocyte fatty acid desaturation/elongation pathway observed in all species and groups at this final sampling were considerably lower than those observed at the initial sampling (Figs. 1 and 3).

\section{Discussion}

The two experimental diets have fatty acid compositions that represent the two extremes of diet that these salmonids could be consuming in freshwater. The FO diet has a fatty acid composition that will be similar to the fatty acid composition of the diet in fish consuming a predominantly piscivorous diet. The VO diet was formulated to represent the fatty acid composition of the diet in fish consuming a more insectivorous/planktonivorous diet. As such these diets represent the extremes as all the fish in this study would, in the wild, probably consume a mixed diet containing both insects/zooplankton/molluscs etc. and small fish.

At the initiation of the dietary trial, significant differences in the activity of the hepatocyte fatty acid desaturation pathway were observed between the different salmonids with the rank order in the present study being brown trout $>$ Atlantic salmon $\geq$ Arctic charr. Interestingly, comparison of the data from previous studies on salmonids showed that the apparent rank order for the desaturation of 18:3n-3 to HUFA in the different species fed diets containing fish oil was rainbow trout $>$ Atlantic salmon $\geq$ Arctic charr (Olsen and Ringo, 1992; Buzzi et al., 1996; Bell et al., 1997; Tocher et al., 2000). These 
earlier studies had many methodological differences with the Arctic charr data being obtained from in vivo ${ }^{14} \mathrm{C}$-fatty acid injection studies (Olsen and Ringo, 1992), whereas the rainbow trout and salmon studies both used isolated hepatocytes. However, the methods for isolating the cells varied between these hepatocyte studies and the trout were maintained in indoor aquaria under controlled photoperiod (Buzzi et al., 1996) whereas the salmon trials were performed under natural photoperiod in outdoor tanks (Bell et al., 1997; Tocher et al., 2000). Diets and feeding regimes also varied in all the previous studies. Therefore it is noteworthy that, despite these differences, both the earlier studies and the present study have indicated a similar pattern with trout species tending to be the most active in desaturation with the charr the least active and salmon intermediate. In an earlier dietary trial, which did not measure desaturase activities directly, the tissue fatty acid compositions obtained alone prompted the authors to suggest that $\Delta 6$ and/or $\Delta 5$ desaturases may be less efficient in Arctic charr than in rainbow trout (Yang and Dick, 1994).

Differences between the salmonids in liver polar lipid fatty acid compositions were also observed in the present study with the Arctic charr showing higher percentages of monoenes and lower DHA, n3PUFA and total PUFA compared to the brown trout and salmon. In an earlier study, liver polar lipids in Arctic charr also showed higher levels of monoenes (and to a lesser extent 18:1n-9) and slightly lower n-3 PUFA than rainbow trout (Yang and Dick, 1994). The effects of diets containing vegetable oils on tissue fatty acid compositions are quite well documented, particularly in salmon, but they do vary somewhat depending upon the precise fatty acid compositions of the diets. Previously, we showed that salmon smolts fed linseed oil (18:3n-3 and 18:2n-6 in a ratio of about 3:1) showed increased 18:3n-3 and EPA but reduced DHA in liver phospholipids (Bell et al., 1993). Diets rich in 18:2n-6 alone (sunflower oil) have previously been shown to increase 18:2n-6, AA and total n-6PUFA and decrease EPA and DHA levels in liver polar lipids in salmon smolts (Bell et al., 1991,1993). In the present trial, feeding salmon parr the rapeseed/linseed oil (VO) diet (rich in both 18:2n-6 and 18:3n-3) increased the levels of 18:2n-6 and total n-6PUFA but not AA, and increased 18:3n-3 but decreased DHA in both Atlantic salmon and brown trout. Therefore, including high 18:3n-3 in the diet has inhibited the production of AA from 18:2n-6. Similarly, the presence of high 18:2n-6 and 18:3n-3 in the diet may lower the levels of DHA by competing with 24:5n-3 for $\Delta 6$ desaturase and thus preventing the conversion of 24:5n-3 to 24:6n-3 (see Sprecher and Chen, 1999; Sprecher et al., 1999), thereby reducing the production of DHA. Consistent with this, dietary soy bean oil increased both $18: 2 \mathrm{n}-6$ and 18:3n-3, decreased EPA and DHA, and had little effect on AA in polar and neutral lipids in serum lipoproteins in salmon, compared to fish fed a diet containing fish oil (Lie et al., 1993). Brown trout in 
seawater fed 18:2n-6-rich corn oil compared to fish oil showed increased levels of 18:2n-6 and 20:3n6, but not AA, and lower levels of n-3 fatty acids in liver lipid (Arzel et al., 1994). In an earlier study, rainbow trout fed linseed oil showed increased 18:3n-3 in liver and muscle polar and neutral lipids, but interestingly no significant increase in EPA and DHA was reported (Sowizral et al., 1990).

In contrast, in the present trial in both the Arctic charr groups fed the VO diet, there was no increase in 18:3n-3 in liver polar lipid and the level of DHA was not decreased, while there was only a modest increase in the levels of 18:2n-6, total n-6PUFA and AA, with the latter not increased in salmon and brown trout fed the VO diet. There are no data on feeding Arctic charr diets equally rich in both 18:3n-3 and 18:2n-6 for direct comparison. However, Arctic charr fed linseed oil showed no increase in 18:2n-6 or AA but increased 18:3n-3 and reduced EPA and DHA in liver polar lipid (Yang and Dick, 1994). Brook charr (Salvelinus fontinalis) fed soy bean oil or rapeseed oil had quite substantially increased 18:2n-6 and decreased EPA and DHA in flesh total lipid compared to charr fed a diet containing fish (menhaden) oil (Guillou et al., 1995). The difference between the Arctic charr and trout or salmon has also not been observed previously as Yang and Dick (1994) found no major difference between Arctic charr and rainbow trout in the effects of feeding linseed oil on liver polar lipid fatty acid compositions. Differences between data from Arctic charr in the different studies are likely to be at least partly due to variations between strains although it was noteworthy how similar the fatty acid compositions and the effects of feeding VO diet were in the two charr populations used in the present study.

Hepatocyte fatty acyl desaturation was significantly greater in the present study in all of the salmonid species and groups fed the VO diet compared to the FO diet. The activity ranged from being 1.8-fold greater in the brown trout to over 2.8-fold greater in the F1 salmon with the other 3 groups being 2.4- to 2.6-fold greater. In our previous studies on salmon during the period of parr-smolt transformation, the peak activity of hepatocyte fatty acyl desaturation of $\left[1-{ }^{14} \mathrm{C}\right] 18: 3 \mathrm{n}-3$ was 2.5 -fold greater in fish fed a diet containing a 1:1 blend of rapeseed/linseed oil compared to a diet containing fish oil (Bell et al., 1997). In a similar recent study of salmon during smoltification, the peak activity of hepatocyte fatty acyl desaturation of $\left[1-{ }^{14} \mathrm{C}\right] 18: 3 \mathrm{n}-3$ was 2.4-fold and 1.4-fold greater in fish fed diets containing rapeseed oil or linseed oil, respectively, compared to a diet containing fish oil (Tocher et al., 2000). Buzzi et al. (1996) showed that in rainbow trout fed an olive oil diet (containing 18:2n-6), the recovery of radiolabelled DHA in polar lipids from hepatocytes incubated with $\left[1-{ }^{14} \mathrm{C}\right] 18: 3 \mathrm{n}-3$ was double that of fish fed a diet containing fish oil. The recovery of desaturated products of intraperitoneally injected $\left[1-{ }^{14} \mathrm{C}\right] 18: 3 \mathrm{n}-3$ and $\left[1-{ }^{14} \mathrm{C}\right] 18: 2 \mathrm{n}-6$ from Arctic charr was increased 
considerably in fish fed diets containing $1 \% 18: 2 n-6$ or $1 \% 18: 3 n-3$ compared to fish fed a commercial, fish oil-containing diet (Olsen and Ringo, 1992).

Based on the fatty acid compositions alone, and their response to feeding the VO diet, Arctic charr appear to be an interesting species to study in relation to vegetable oil diets as the increase in liver $18: 2 n-6$ and 18:3n-3 was lowest and there was virtually no decrease in 22:6n-3 compared to the trout and salmon. The above suggested that Arctic charr were better able to desaturate 18:3n-3 to DHA and also 18:2n-6 to AA. However, it was interesting that this was not entirely reflected in the liver hepatocyte desaturase activities as both groups of charr displayed lower overall activity of the desaturase pathway than brown trout and Atlantic salmon at the initiation of the trial. After feeding the VO diet, the desaturase activity in the $\mathrm{C}$-charr was increased to the highest level of all the groups which is consistent with the fatty acid composition data but with the R-charr, although hepatocyte fatty acid desaturation increased, it was still lower than in brown trout and salmon. Indeed it was curious that hepatocyte fatty acid desaturation was different in the two charr groups, despite there being essentially no significant difference between the liver polar lipid fatty acid compositions although some caution must be used in interpreting strain differences with samples of $n=3$. In contrast, hepatocyte desaturation was not significantly different between the wild Scottish Atlantic salmon and the F1 crosses of the Scottish Atlantic salmon with the Canadian land-locked salmon (F1 salmon) when fed fish oil.

Another interesting result from the present study was the observation of an apparent temporal effect. Activities recorded at the initial sampling were some 10-fold, and 5-fold higher than the activities recorded in fish fed the FO and VO diets, respectively, at the end of the trial. The exact reasons for this temporal difference are not known but we can speculate on possible contributing factors such as water temperature, photoperiod (fish were on natural photoperiod prior to the trial but on $12 \mathrm{~h}$ light: $12 \mathrm{~h}$ dark during the trial), diet, appetite and feeding pattern. We have previously observed changes in hepatocyte desaturase activity in salmon with time although this was also related to parr-smolt transformation (Bell et al., 1997: Tocher et al., 2000). However, cues such as photoperiod and water temperature can directly affect appetite and consequent feeding pattern as has been shown with maturing Atlantic salmon in seawater (Kadri et al., 1996; Blyth et al., 1999) and anadromous Arctic charr (Jorgensen et al., 1997) but, more importantly with respect to the present study, also with freshwater salmon parr (Simpson et al., 1996). A further possibility is that the difference could be related to diet as the fish were being fed a different diet up until the initiation of the experiment. This diet was a standard salmonid diet containing Northern hemisphere fish oil and as 
such had a fatty acid composition slightly different to the experimental (control) diet containing Southern hemisphere fish oil.

\section{Conclusions}

Hepatocyte desaturation and elongation of $\left[1-{ }^{14} \mathrm{C}\right] 18: 3 \mathrm{n}-3$ and the effects of feeding a vegetable oil diet containing a 1:1 blend of linseed and rapeseed oils were investigated in three different species of salmonids indigenous to Scotland, as well as an F1 cross of scottish wild salmon to Canadian landlocked salmon.

1. Hepatocyte fatty acid desaturation/elongation activity at the initiation of the trial was greatest in brown trout, followed by wild Atlantic salmon and then Arctic charr.

2. The desaturation activity was higher in fish from all species when fed the diet containing vegetable oil compared to fish fed a control diet containing fish oil.

3. There was an apparent temporal effect in that the desaturation activity was higher in all species at the initial sampling compared to the final sampling 3 months later.

4. Liver polar lipid fatty acid compositions of salmon and brown trout were very similar to each other, and different to Arctic charr which showed lower total n-3PUFA and DHA, but higher EPA and monoenes than the other salmonids.

5. Feeding the vegetable oil diet increased the levels of 18:2n-6, total n-6PUFA and 18:3n-3 and decreased DHA and n-3/n-6 ratio in salmon and brown trout liver polar lipids. In contrast, there was only a modest increase in 18:2n-6 and total n-6PUFA, but AA was increased, and there was no increase in 18:3n-3 and the level of DHA was not decreased in Arctic charr fed the diet containing vegetable oil.

6. The results indicated that there were significant differences in hepatic PUFA metabolism between Arctic charr and other the salmonids that could have important consequences both physiologically and in their ability to be successfully cultured on diets containing vegetable oils.

\section{Acknowledgements}

We would like to thank Trouw Aquaculture for preparing experimental diets. We are also grateful to the staff of the Fisheries Research Service, Marine Research Unit at Aultbea for their expertise in fish husbandry. 


\section{References}

Ackman, R.G., 1980. Fish lipids, part 1. In: Connell, J.J., (Ed.), Advances in Fish Science and Technology. Fishing News Books, Farnham, U.K. pp. 87-103.

Arzel, J., Lopez, F.X.M., Metailler, R., Stephan, G., Viau, M., Ganderner, G., Guillaume, J., 1994. Effect of dietary lipid on growth performance and body composition of brown trout (Salmo trutta) reared in seawater. Aquaculture 123, 361-375.

Bell, J.G., Dick, J.R., Sargent, J.R., 1993. Effects of diets rich in linoleic or $\alpha$-linolenic acid on phospholipid fatty acid composition and eicosanoid production in Atlantic salmon (Salmo salar). Lipids 28, 819-826.

Bell, J.G., Ghioni, C., Sargent, J.R., 1994. Fatty acid compositions of 10 freshwater invertebrates which are natural food organisms of Atlantic salmon parr (Salmo salar): A comparison with commercial diets. Aquaculture 128, 301-313.

Bell, J.G., McVicar, A.H., Park, M.T., Sargent, J.R., 1991. High dietary linoleic acid affects the fatty acid compositions of individual phospholipids from tissues of Atlantic salmon (Salmo salar): Association with stress susceptibility and cardiac lesion. J. Nutr. 121, 1163-1172.

Bell, J.G., Tocher, D.R., Farndale, B.M., Cox, D.I., McKinney, R.W., Sargent, J.R., 1997. The effect of dietary lipid on polyunsaturated fatty acid metabolism in Atlantic salmon (Salmo salar) undergoing parr-smolt transformation. Lipids 32, 515-525.

Blyth, P.J., Kadri, S., Valdimarsson, S.K., Mitchell, D.F., Purser, G.J., 1999. Diurnal and seasonal variation in feeding patterns of Atlantic salmon, Salmo salar L., in sea cages. Aquaculture Res. $30,539-544$.

Brenner, R.R., 1981. Nutritional and hormonal factors influencing desaturation of essential fatty acids. Prog. Lipid Res. 20, 41-47.

Buzzi, M., Henderson, R.J., Sargent, J.R., 1996. The desaturation and elongation of linolenic acid and eicosapentaenoic acid by hepatocytes and liver microsomes from rainbow trout (Oncorhyncus mykiss) fed diets containing fish oil or olive oil. Biochim. Biophys. Acta 1299, 235-244.

Buzzi, M., Henderson, R.J., Sargent, J.R., 1997. The biosynthesis of docosahexaenoic acid [22:6(n-3)] from linolenic acid in primary hepatocytes isolated from wild northern pike. J. Fish. Biol. 51, 1197-1208.

Christie, W.W., 1982. Lipid Analysis 2nd Edition. Pergamon Press, Oxford. 
Folch, J., Lees, M., Sloane-Stanley, G.H., 1957. A simple method for the isolation and purification of total lipids from animal tissues. J. Biol. Chem. 226, 497-509.

Ghioni, C., Tocher, D.R., Sargent, J.R., 1997. The effect of culture on morphology, lipid and fatty acid composition, and polyunsaturated fatty acid metabolism of rainbow trout (Oncorhynchus mykiss) skin cells. Fish Physiol. Biochem. 16, 499-513.

Guillou, A., Soucy, P., Khalil, M., Adambounou, L., 1995. Effects of dietary vegetable and marine lipid on growth, muscle fatty acid composition and organoleptic quality of flesh of brook charr (Salvelinus fontinalis). Aquaculture 136, 351-362.

Henderson, R.J., Park, M.T., Sargent, J.R., 1995. The desaturation and elongation of ${ }^{14}$ C-labelled polyunsaturated fatty acids by pike (Esox lucius L.) in vivo. Fish Physiol. Biochem. 114, 223235 .

Henderson, R.J., Tocher, D.R., 1987. The lipid composition and biochemistry of freshwater fish. Prog. Lipid Res. 26, 281-347.

Holman, R.T., 1986. Control of polyunsaturated fatty acids in tissue lipids. J. Am. Coll. Nutr. 5, 183211.

Jorgensen, E.H., Johansen, S.J.S., Jobling, M., 1997. Seasonal patterns of growth, lipid deposition and lipid depletion in anadromous Arctic charr. J. Fish. Biol. 51, 312-326.

Kadri, S., Mitchell, D.F., Metcalfe, N.B., Huntingford, F.A., Thorpe, J.E., 1996. Differential patterns of feeding and resource accumulation in maturing and immature Atlantic salmon, Salmo salar. Aquaculture 142, 245-257.

Kanazawa, A., 1985. Essential fatty acid and lipid requirement of fish. In: Cowey, C.B., Mackie, A.M., Bell, J.G. (Eds.), Nutrition and Feeding of Fish. Academic Press, London, pp. 281-298.

Lie, O., Sandvin, A., Waagbo, R., 1993. Influence of dietary fatty acids on the lipid composition of lipoproteins in farmed Atlantic salmon (Salmo salar). Fish. Physiol. Biochem. 12, 249-260.

Lowry, O.H., Rosebrough, N.J., Farr, A.L, Randall, R.J., 1951. Protein measurement with the folin phenol reagent. J. Biol. Chem. 193, 265-275.

Mourente, G., Tocher, D.R., 1993. Incorporation and metabolism of ${ }^{14} \mathrm{C}$-labelled polyunsaturated fatty acids in wild-caught juveniles of golden grey mullet, Liza aurata, in vivo. Fish Physiol. Biochem. 12, 119130.

Mourente, G., Tocher, D.R., 1994. In vivo metabolism of $\left[1-{ }^{14} \mathrm{C}\right]$ linolenic acid $(18: 3 n-3)$ and [1${ }^{14} \mathrm{C}$ ]eicosapentaenoic acid (20:5n-3) in a marine fish. Time course of the desaturation/elongation pathway. Biochim. Biophys. Acta 1212, 109-118. 
Olsen, R.E., Ringo, E., 1992. Lipids of Arctic charr, Salvelinus alpinus (L.) II. Influence of dietary fatty acids on the elongation and desaturation of linoleic and linolenic acids. Fish Physiol. Biochem. 9, 393-399.

Owen, J.M., Adron, J.A., Middleton, C., Cowey, C.B., 1975. Elongation and desaturation of dietary fatty acids in turbot (Scophthalmus maximus) and rainbow trout (Salmo gairdneri). Lipids 10, 528-531.

Sargent, J.R., Bell, J.G., Bell, M.V., Henderson, R.J., Tocher, D.R., 1995. Requirement criteria for essential fatty acids. J. Appl. Ichthyol. 11, 183-198.

Sargent, J.R., Bell, J.G., McEvoy, L., Tocher, D.R., Estevez, A., 1999. Recent developments in the essential fatty acid nutrition of fish. Aquaculture 177, 191-199.

Sargent, J.R., Henderson, R.J., Tocher, D.R., 1989. The lipids. In: Halver, J.E. (Ed.), Fish Nutrition. Academic Press, New York, pp. 154-218.

Sargent, J.R., Tacon, A., 1999. Development of farmed fish: a nutritionally necessary alternative to meat. Proc. Nutr. Soc. 58, 377-383.

Simpson, A.L., Metcalfe, N.B., Huntingford, F.A., Thorpe, J.E., 1996. Pronounced seasonal differences in appetite of Atlantic salmon parr, Salmo salar: Effects of nutritional state and life-history strategy. Funct. Ecol. 10,760-767.

Sprecher, H., Chen, Q., 1999. Polyunsaturated fatty acid biosynthesis: a microsomal-peroxisomal process. Prostaglandins Leukotrienes Essent. Fatty Acids 60, 317-321.

Sprecher, H., Chen, Q., Yin, F.Q., 1999. Regulation of the biosynthesis of 22:5n-6 and 22:6n-3:A complex intracellular process. Lipids 34(Suppl.S), S153-S156.

Sowizral, K.C., Rumsey, G.L., Kinsella, J.E., 1990. Effect of $\alpha$-linolenic acid on n-3 fatty acids of rainbow trout lipids. Lipids 25, 246-253.

Tocher, D.R., Bell, J.G., Dick, J.R., Sargent, J.R., 1997. Fatty acyl desaturation in isolated hepatocytes from Atlantic salmon (Salmo salar): Stimulation by dietary borage oil containing $\gamma$-linolenic acid. Lipids 32, 1237-1247.

Tocher, D.R., Bell, J.G., Henderson, R.J., McGhee, F., Mitchell, D., Morris, P.C., 2000. The effect of dietary linseed and rapeseed oils on polyunsaturated fatty acid metabolism in Atlantic salmon (Salmo salar) undergoing parr-smolt transformation. Fish Physiol. Biochem. 23, 59-73.

Tocher, D.R., Sargent, J.R., Frerichs, G.N., 1988. The fatty acid compositions of established fish cell lines after long-term culture in mammalian sera. Fish Physiol. Biochem. 5, 219-227. 
U.S. National Research Council. 1993. Nutrient requirements of fish. National Academy Press, Washington, D.C.

Watanabe, T., 1982. Lipid nutrition in fish. Comp. Biochem. Physiol. 73B, 3-15.

Wilson, R., Sargent, J.R., 1992. High resolution separation of polyunsaturated fatty acids by argentation thin-layer chromatography. J. Chromatogr. 623, 403-407.

Yang, X., Dick, T.A., 1994. Arctic char (Salvelinus alpinus) and rainbow trout (Oncorhynchus mykiss) differ in their growth and lipid metabolism in response to dietary polyunsaturated fatty acids. Can J. Fish Aquat. Sci. 51, 1391-1400.

Zar, J.H., 1984. Biostatistical Analysis, 2nd Edition. Prentice-Hall , Englewood Cliffs. 
Legends to Figures:

FIG. 1 Total fatty acid desaturation activity in hepatocytes from salmonids at the initiation of the dietary trial. Results represent the rate of conversion $\left(\mathrm{pmol} \cdot \mathrm{h}^{-1} \mathrm{mg}\right.$ liver protein $\left.{ }^{-1}\right)$ of $\left[1-{ }^{14} \mathrm{C}\right] 18: 3 \mathrm{n}-3$ to desaturated products and are means \pm S.D. $(n=3)$. Significance of differences between means were determined by one-way analysis of variance (ANOVA) followed by Tukey's post test, and are denoted by different letters $(\mathrm{P}<0.05)$.

FIG. 2 Products of desaturation of $\left[1-{ }^{14} \mathrm{C}\right] 18: 3 n-3$ in hepatocytes from salmonids at the initiation of the dietary trial. Results represent the rates of conversion $\left(\mathrm{pmol} \cdot \mathrm{h}^{-1} \cdot \mathrm{mg}\right.$ liver protein $\left.{ }^{-1}\right)$ of $\left[1-{ }^{14} \mathrm{C}\right] 18: 3 \mathrm{n}-3$ to individual desaturated/elongated fatty acid products and are means \pm S.D. $(n=3)$.

FIG.3. Effect of diet on the total fatty acid desaturation activity in hepatocytes from salmonids at the termination of the dietary trial. Results represent the rate of conversion (pmol. $\mathrm{h}^{-1} \cdot \mathrm{mg}$ liver protein ${ }^{-1}$ ) of $\left[1-{ }^{14} \mathrm{C}\right] 18: 3 n-3$ to desaturated products and are means \pm S.D. $(n=3)$. Significance of differences due to diet and species were determined by two-way analysis of variance (ANOVA) with both parameters showing highly significant effects; Species, $\mathrm{P}=0.0003$ (F-value $=8.87$ ), with R-charr having the significantly lowest activity; Diet, $\mathrm{P}<0.0001$ (F-value, 108.61) VO > FO; There was no significant interaction between the parameters ( $\mathrm{P}=0.0867$; F-value, 2.37) indicating that the diet had the same affect with all species. 
Fig.1.

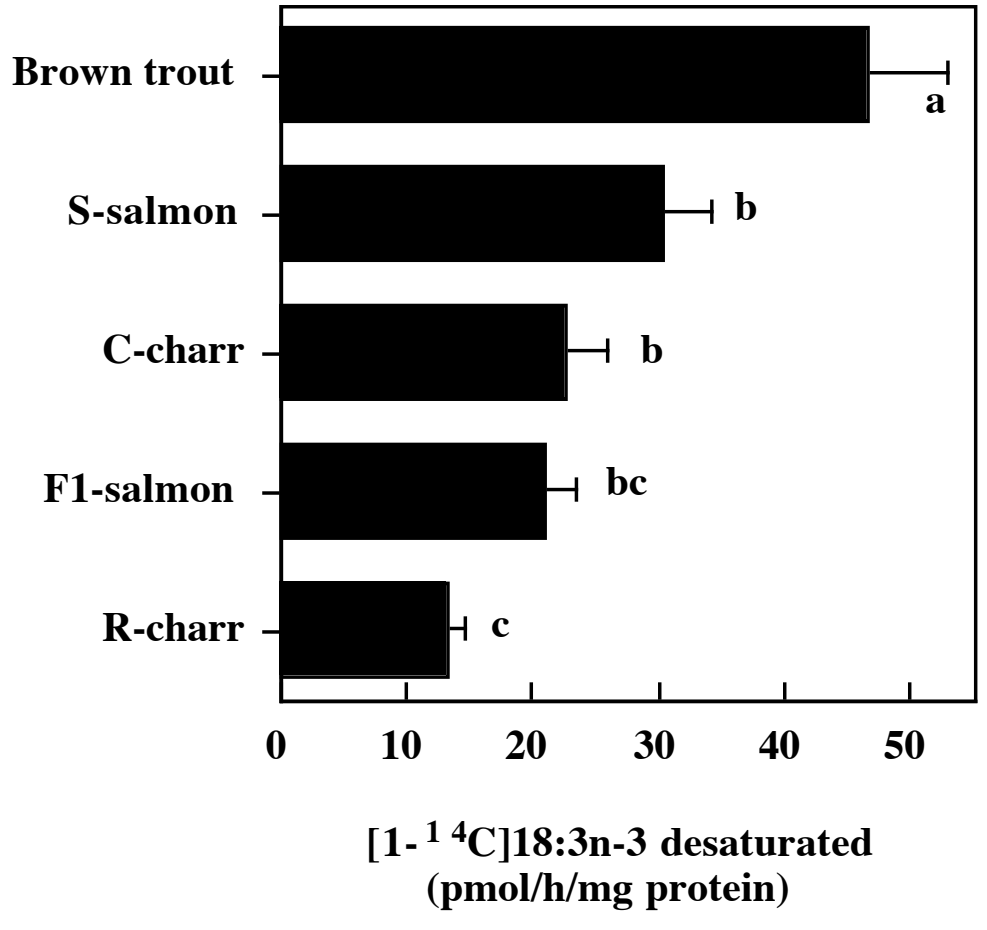


Fig.2

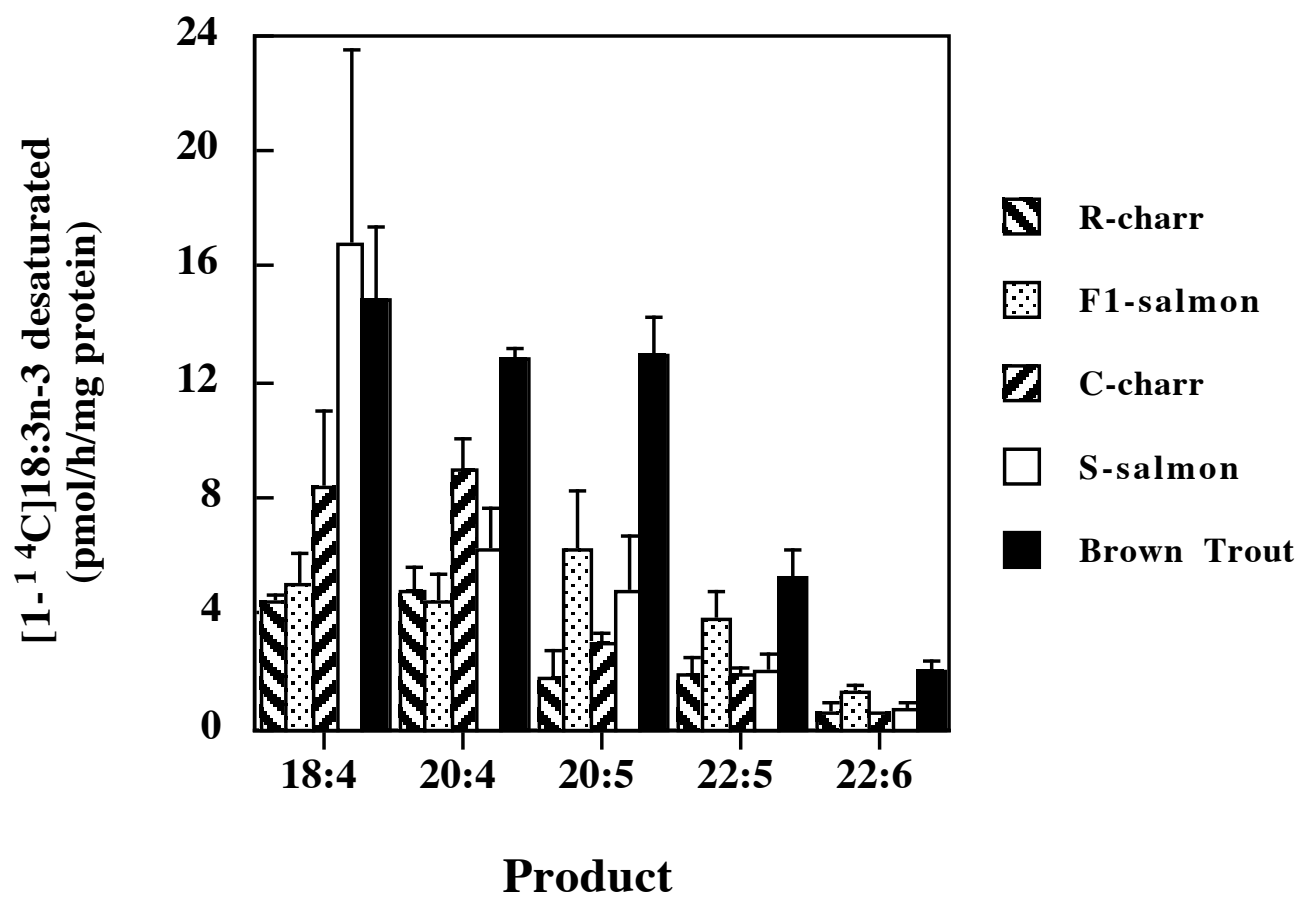


Fig.3

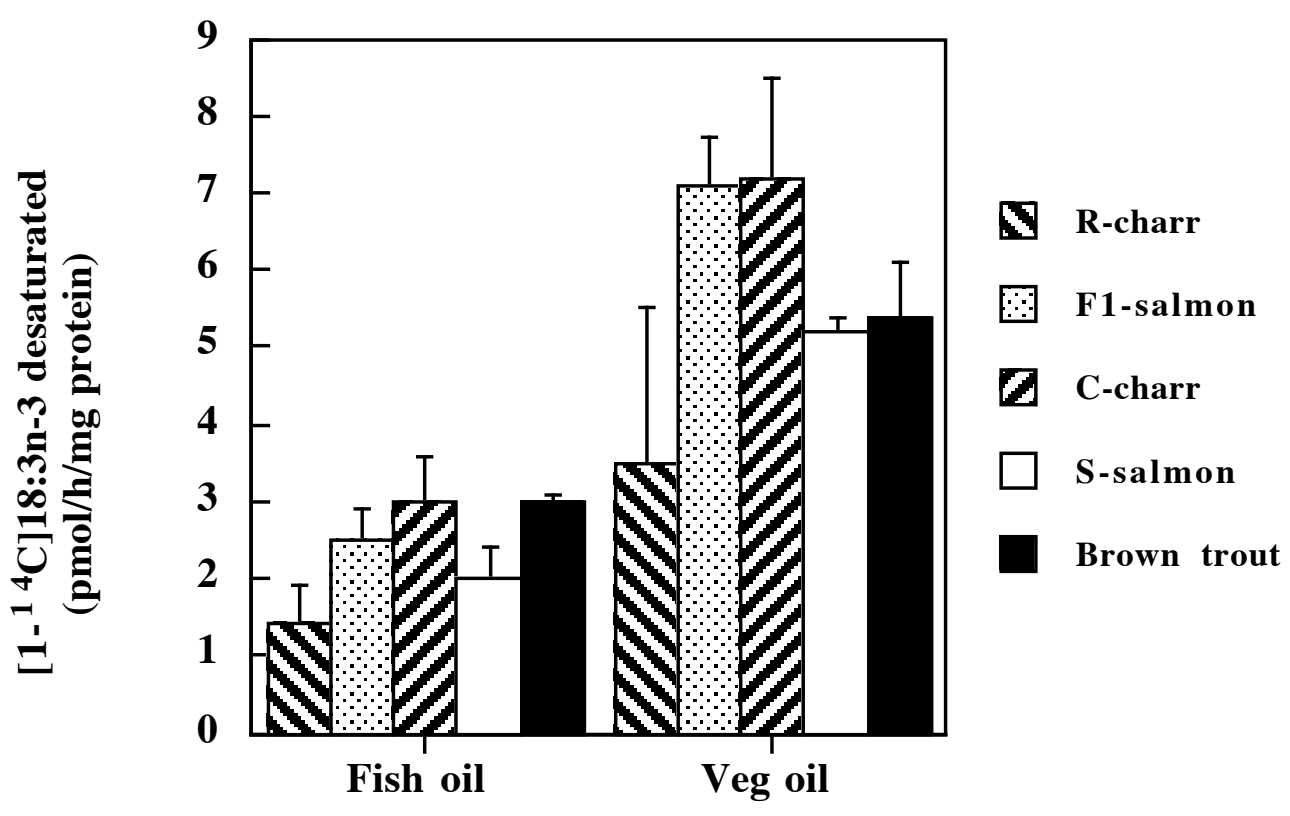

Diet 


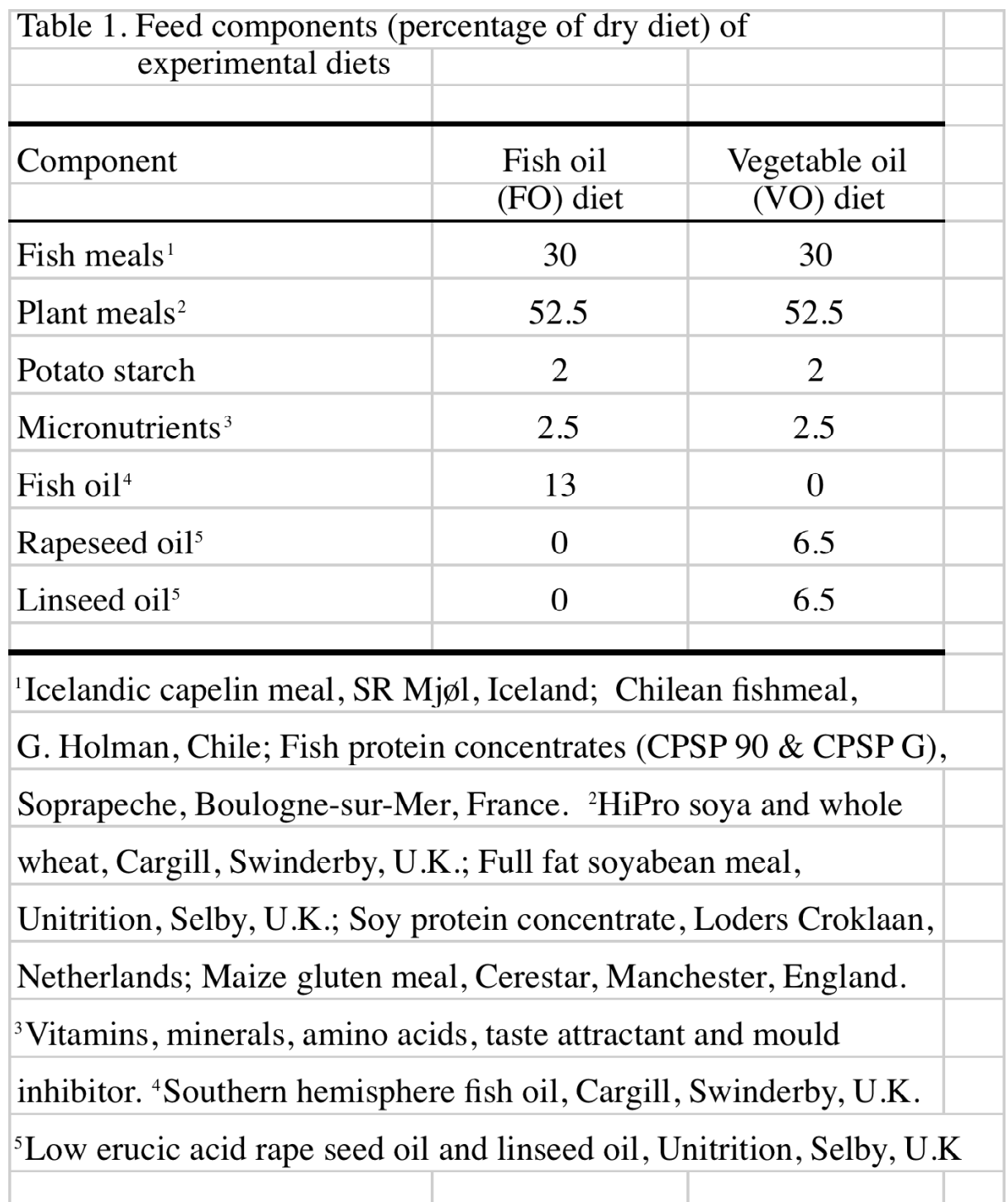


Table 2. Fatty acid (Percentage by weight of total fatty acids) composition of diets.

\begin{tabular}{|c|c|c|c|}
\hline Fatty acid & Pre-trial diet & $\begin{array}{c}\text { Fish oil } \\
\text { (FO) diet }\end{array}$ & $\begin{array}{l}\text { Vegetable oil } \\
\text { (VO) diet }\end{array}$ \\
\hline $14: 0$ & 5.1 & 5.9 & 1.1 \\
\hline $16: 0$ & 16.0 & 15.2 & 7.8 \\
\hline 18:0 & 2.0 & 2.7 & 2.8 \\
\hline Total saturates $^{1}$ & 24.3 & 24.6 & 12.3 \\
\hline $16: 1(n-7)$ & 5.1 & 6.7 & 1.4 \\
\hline $18: 1(n-9)$ & 16.2 & 11.6 & 29.8 \\
\hline $18: 1(n-7)$ & 2.5 & 2.8 & 2.2 \\
\hline $20: 1(n-9)$ & 6.8 & 5.7 & 2.5 \\
\hline $22: 1(n-11)$ & 9.8 & 7.6 & 2.2 \\
\hline $22: 1(n-9)$ & 0.1 & 0.7 & 0.4 \\
\hline $24: 1$ & 1.6 & 0.7 & 0.3 \\
\hline Total monoenes ${ }^{2}$ & 42.8 & 36.1 & 38.9 \\
\hline $18: 2(n-6)$ & 5.2 & 7.4 & 18.5 \\
\hline $20: 2(n-6)$ & 0.4 & 0.4 & 0.1 \\
\hline $20: 4(n-6)$ & 0.6 & 0.5 & 0.2 \\
\hline Total (n-6)PUFA ${ }^{3}$ & 7.1 & 8.6 & 18.8 \\
\hline $18: 3(n-3)$ & 1.7 & 1.5 & 24.2 \\
\hline $18: 4(n-3)$ & 2.5 & 2.6 & 0.7 \\
\hline $20: 4(n-3)$ & 0.6 & 0.6 & 0.1 \\
\hline $20: 5(n-3)$ & 7.5 & 13.5 & 2.0 \\
\hline $22: 5(n-3)$ & 0.8 & 1.7 & 0.2 \\
\hline $22: 6(n-3)$ & 11.9 & 7.2 & 2.5 \\
\hline Total (n-3) PUFA & 25.2 & 27.1 & 29.8 \\
\hline Total PUFA ${ }^{4}$ & 33.1 & 39.4 & 48.8 \\
\hline$(n-3) /(n-6)$ & 3.5 & 3.2 & 1.6 \\
\hline
\end{tabular}

Values are means of two replicate measurements. 'Includes 15:0, 17:0, 20:0 and 22:0. ${ }^{2}$ Includes 16:1n-9, 20:1n-11 and 20:1n-7.

${ }^{3}$ Includes 18:3n-6, 20:3n-6 and 22:5n-6. Includes 18:2n-9 and C16 PUFA. PUFA, polyunsaturated fatty acids. 
Table 3. Effect of diets on the total lipid content (percentage of wet weight) of livers of salmonids

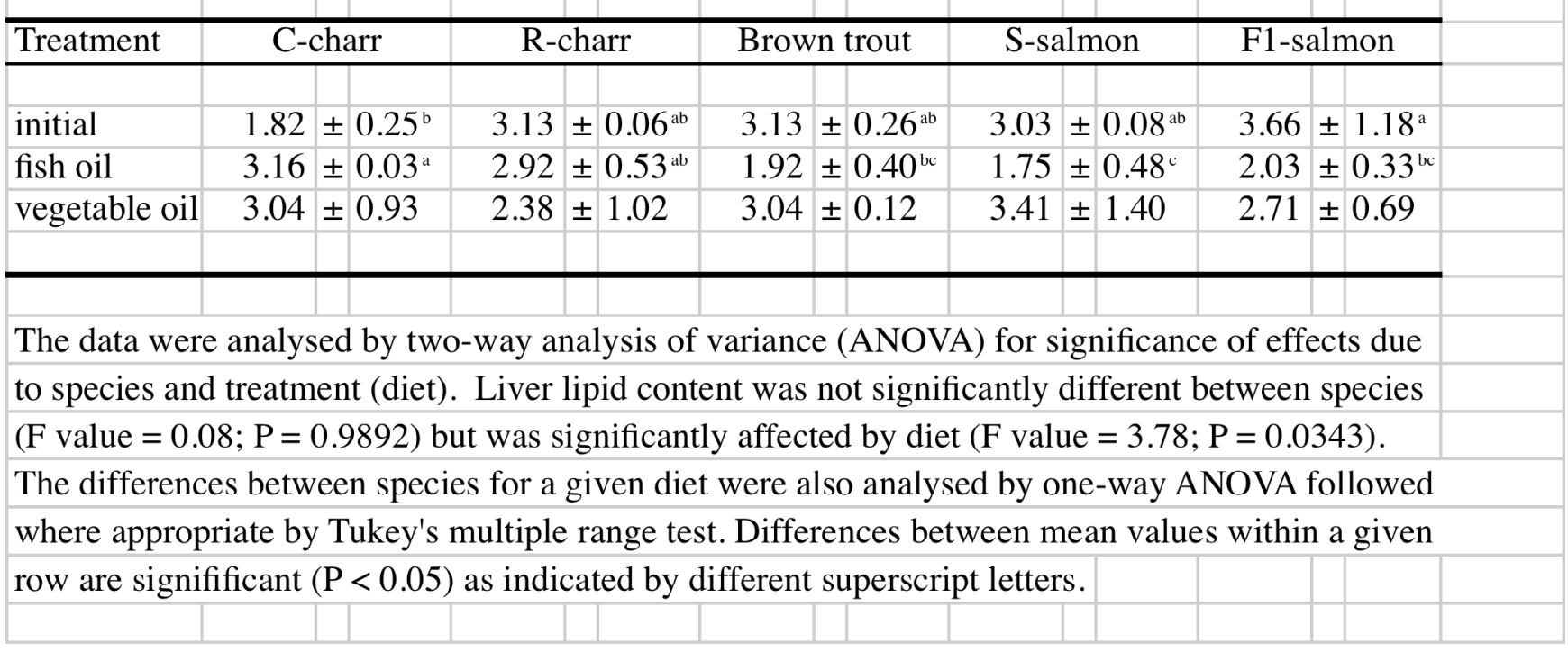


Table 4. Fatty acid composition of total polar lipid of livers from salmonids at the initiation of the dietary trial.

\begin{tabular}{|c|c|c|c|c|c|c|c|c|c|c|c|c|c|c|c|c|c|c|c|}
\hline Fatty acid & \multicolumn{2}{|c|}{ C-Charr } & & \multicolumn{3}{|c|}{ R-Charr } & & \multicolumn{4}{|c|}{ Brown trout } & \multicolumn{3}{|c|}{ S-salmon } & & \multicolumn{4}{|c|}{ F1-salmon } \\
\hline $14: 0$ & 1.5 & \pm 0.2 & ab & 0.9 & \pm & $\overline{0.4}$ & & 1.7 & & 0.1 & & 1.6 & \pm & $\overline{0.3}$ & ab & 1.6 & & 0.2 & $\mathrm{ab}$ \\
\hline $15: 0$ & 0.2 & \pm 0.1 & & 0.3 & \pm & 0.1 & & 0.4 & & 0.0 & & 0.4 & \pm & 0.1 & & 0.2 & & 0.1 & \\
\hline $16: 0$ & 20.3 & \pm 3.3 & & 18.0 & \pm & 1.8 & & 22.7 & \pm 1 & 1.5 & & 24.2 & \pm & 3.7 & & 21.9 & \pm & 1.1 & \\
\hline $17: 0$ & 0.2 & \pm 0. & & 0.2 & \pm & 0.0 & & 0.4 & & 0.1 & & 0.4 & \pm & 0.1 & & 0.3 & & 0.1 & \\
\hline 18:0 & 4.8 & $\pm 1 . t$ & & 4.7 & \pm & 0.8 & & 4.2 & & 0.3 & & 5.4 & \pm & 0.6 & & 5.6 & \pm & 0.5 & \\
\hline Total saturates ${ }^{1}$ & 27.2 & \pm 1. & ab & 24.1 & \pm & 1.8 & b & 29.5 & \pm 1 & 1.4 & $\mathrm{ab}$ & 32.0 & \pm & 4.3 & a & 29.7 & \pm & 1.2 & ab \\
\hline $16: 1 n-9$ & $0 ?$ & +02 & & 03 & + & 01 & & 03 & & 03 & & 03 & + & 02 & & 03 & -1 & 00 & \\
\hline $16: 1 n-7$ & 2.9 & \pm 1.1 & a & 0.8 & \pm & 0.1 & 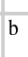 & 2.0 & & 0.5 & ab & 1.5 & \pm & 0.4 & ah & 1.5 & \pm & 0.3 & hc \\
\hline $18: 1 n-9$ & 13.7 & \pm 1.5 & b & 16.6 & \pm & 1.0 & $a^{a}$ & 9.8 & & 0.5 & & 9.2 & \pm & 0.8 & c & 9.0 & \pm & 0.4 & c \\
\hline $18: 1 n-7$ & 1.7 & \pm 1.7 & & 3.1 & \pm & 0.7 & & 1.7 & & 0.1 & & 1.6 & \pm & 0.1 & & 1.2 & \pm & 0.2 & \\
\hline $20: 1^{2}$ & 2.9 & \pm 1.7 & & 4.4 & \pm & 1.6 & & 1.8 & & 0.1 & & 1.9 & \pm & 0.2 & & 1.8 & \pm & 0.2 & \\
\hline $22: 1$ & 0.4 & \pm 0. & & 0.3 & \pm & 0.1 & & 0.5 & & 0.1 & & 0.5 & \pm & 0.1 & & 0.6 & \pm & 0.1 & \\
\hline $24: 1$ & 0.8 & \pm 0.2 & & 0.7 & \pm & 0.1 & & 1.0 & & 0.2 & & 1.2 & \pm & 0.3 & & 0.6 & \pm & 0.4 & \\
\hline Total monoenes & 22.8 & \pm 1.2 & b & 26.2 & \pm & 1.2 & & 17.2 & \pm 0 & 0.4 & c & 16.1 & \pm & 1.5 & c & 15.2 & \pm & 0.9 & c \\
\hline $18: 2 n-6$ & 2.1 & \pm 0.3 & & 1.9 & \pm & 0.5 & & 1.9 & & 0.2 & & 1.9 & \pm & 0.2 & & 1.9 & \pm & 0.1 & \\
\hline $20: 2 n-6$ & 0.6 & \pm 0. & & 0.4 & \pm & 0.2 & & 0.4 & & 0.0 & & 0.4 & \pm & 0.1 & & 0.5 & \pm & 0.0 & \\
\hline $20: 3 n-6$ & 0.4 & \pm 0.1 & & 0.2 & \pm & 0.0 & & 0.3 & & 0.1 & & 0.3 & \pm & 0.1 & & 0.5 & \pm & 0.2 & \\
\hline $20: 4 n-6$ & 2.1 & \pm 0. & c & 3.9 & \pm & 0.5 & $\mathrm{a}$ & 3.3 & \pm( & 0.4 & ab & 2.8 & \pm & 0.3 & bc & 2.6 & \pm & 0.1 & bc \\
\hline $22: 5 n-6$ & 0.5 & \pm 0.1 & ab & 0.2 & \pm & 0.1 & & 0.4 & \pm( & 0.1 & bc & 0.4 & \pm & 0.1 & bc & 0.7 & \pm & 0.1 & c \\
\hline Total n-6PUFA ${ }^{3}$ & 5.9 & \pm 0.3 & & 6.6 & \pm & 0.5 & & 6.6 & \pm 0 & 0.3 & & 6.0 & \pm & 0.1 & & 6.3 & \pm & 0.2 & \\
\hline $18: 3 n-3$ & 0.4 & \pm 0. & & 0.4 & \pm & 0.1 & & 0.4 & & 0.0 & & 0.3 & \pm & 0.0 & & 0.3 & \pm & 0.1 & \\
\hline $18: 4 n-3$ & 0.3 & \pm 0.1 & & 0.1 & \pm & 0.1 & & 0.2 & & 0.0 & & 0.2 & \pm & 0.0 & & 0.1 & \pm & 0.0 & \\
\hline $20: 4 n-3$ & 0.4 & \pm 0.1 & ab & 0.6 & \pm & 0.1 & $\mathrm{a}$ & 0.3 & \pm 0 & 0.0 & b & 0.3 & \pm & 0.1 & b & 0.4 & \pm & 0.0 & ab \\
\hline $20: 5 n-3$ & 7.2 & \pm 0. . & a & 7.2 & \pm & 0.3 & & 4.5 & \pm 0 & 0.7 & & 5.5 & \pm & 0.4 & hc. & 6.1 & \pm & 0.4 & ah \\
\hline $22: 5 n-3$ & 1.2 & \pm 0. & b & 0.2 & \pm & 0.1 & d & 0.9 & \pm( & 0.1 & & 1.2 & \pm & 0.1 & b & 1.5 & \pm & 0.1 & $\mathrm{a}$ \\
\hline $22: 6 n-3$ & 33.8 & \pm 0.3 & b & 32.9 & \pm & 0.5 & b & 39.2 & \pm 1 & 1.2 & & 37.2 & \pm & 5.1 & a & 39.0 & \pm & 1.1 & a \\
\hline Total n-3PUFA ${ }^{4}$ & 43.4 & \pm 0.5 & bc & 41.5 & \pm & 0.7 & & 45.5 & \pm 1 & 1.1 & ab & 44.7 & \pm & 5.6 & ab & 47.5 & \pm & 1.0 & $\mathrm{a}$ \\
\hline Total PUFA' & 49.8 & \pm 0.8 & bc & 48.4 & \pm & 0.7 & & 53.0 & \pm 1 & 1.1 & $\mathrm{ab}$ & 51.6 & \pm & 5.4 & 0 & 54.7 & \pm & 0.9 & \\
\hline$(n-3) /(n-6)$ & 7.4 & \pm 0.2 & & 6.3 & \pm & 0.5 & & 6.9 & & 0.3 & & 7.5 & \pm & 0.8 & & 7.5 & & 0.3 & \\
\hline
\end{tabular}

${ }^{1}$ Includes 20:0 and 22:0; ${ }^{2}$ predominantly n-9 isomer; ${ }^{3}$ Includes 18:3n-6 and 22:4n-6.

${ }^{4}$ Includes 20:3n-3. ${ }^{5}$ Includes C16 PUFA. PUFA, polyunsaturated fatty acids. Data were subjected to one-way ANOVA as described in the Materials and Methods section. Mean values in the same row with a different supcrscript letter are significantly different $(P<0.05)$ as determined by Tukey's test. 
Table 5. Fatty acid composition of total polar lipid of livers from salmonids fed a diet containing fish oil.

\begin{tabular}{|c|c|c|c|c|c|c|c|c|c|c|c|c|c|c|c|c|c|c|c|c|}
\hline \multirow{2}{*}{$\begin{array}{l}\text { Fatty acid } \\
\text { Total saturates }\end{array}$} & \multicolumn{3}{|c|}{ C-charr } & & \multicolumn{3}{|c|}{ R-charr } & & \multicolumn{3}{|c|}{ Brown trout } & & \multicolumn{3}{|c|}{ S-salmon } & & \multicolumn{4}{|c|}{ F1-salmon } \\
\hline & 24.7 & \pm & 2.6 & ab & 23.6 & \pm & 0.4 & b & 25.5 & \pm & 0.4 & ab & 26.6 & & 0.7 & ab & 28.2 & \pm & 1.4 & \\
\hline $16: 1 n-9$ & 0.4 & \pm & 0.1 & & 0.3 & \pm & 0.0 & & 0.3 & \pm & 0.3 & & 0.3 & & 0.2 & & 0.3 & \pm & 0.3 & \\
\hline $16: 1 n-7$ & 1.2 & \pm & 0.2 & $\mathrm{bc}$ & 0.9 & \pm & 0.1 & & 1.9 & \pm & 0.2 & a & 1.6 & \pm & 0.2 & ab & 1.8 & & 0.2 & \\
\hline $18: \ln -9$ & 11.4 & \pm & 1.7 & b & 16.0 & \pm & 0.5 & a & 9.5 & \pm & 0.5 & $\mathrm{bc}$ & 8.8 & \pm & 0.0 & c & 8.1 & \pm & 0.5 & \\
\hline $18: 1 n-7$ & 3.9 & \pm & 0.2 & $\mathrm{a}^{\mathrm{a}}$ & 3.0 & \pm & 0.7 & a & 1.6 & \pm & 0.3 & $\mathrm{~b}$ & 1.5 & \pm & 0.3 & b & 1.6 & \pm & 0.2 & \\
\hline $20: 1 n-11 / 9$ & 4.6 & \pm & 2.5 & $\|^{a}$ & 3.6 & \pm & 0.8 & ab & 2.3 & \pm & 0.0 & ab & 1.7 & \pm & 0.3 & ab & 1.1 & \pm & 0.3 & \\
\hline $20: 1 n-7$ & 0.3 & \pm & 0.1 & & 0.3 & \pm & 0.0 & & 0.2 & \pm & 0.0 & & 0.1 & \pm & 0.1 & & 0.1 & & 0.1 & \\
\hline 22:1n-11 & 0.1 & \pm & 0.1 & c & 0.2 & \pm & 0.1 & c & 0.8 & \pm & 0.1 & a & 0.5 & \pm & 0.1 & b & 0.3 & & 0.1 & \\
\hline $24: 1$ & 0.6 & \pm & 0.1 & & 0.8 & \pm & 0.3 & & 1.2 & \pm & 0.4 & & 1.4 & \pm & 0.5 & & 0.8 & \pm & 0.3 & \\
\hline Total monoenes & 22.5 & \pm & 2.4 & a & 25.3 & \pm & 1.6 & a & 17.7 & \pm & 0.2 & h & 15.9 & \pm & 0.7 & he. & 14.0 & & 0.6 & \\
\hline $18: 2 n-6$ & 1.4 & \pm & 0.3 & 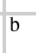 & 1.6 & \pm & 0.5 & ab & 1.9 & \pm & 0.1 & ab & 2.3 & \pm & 0.1 & a & 2.2 & $\perp$ & 0.1 & \\
\hline $18: 3 n-6$ & 0.2 & \pm & 0.1 & & 0.1 & \pm & 0.0 & & 0.2 & \pm & 0.0 & & 0.4 & \pm & 0.3 & & 0.2 & \pm & 0.1 & \\
\hline $20: 2 n-6$ & 1.0 & \pm & 0.3 & a & 0.4 & \pm & 0.1 & b & 0.5 & \pm & 0.0 & b & 0.5 & \pm & 0.1 & $\mathrm{~b}$ & 0.4 & \pm & 0.2 & \\
\hline $20: 3 n-6$ & 0.5 & \pm & 0.4 & & 0.2 & \pm & 0.0 & & 0.3 & \pm & 0.0 & & 0.3 & \pm & 0.0 & & 0.2 & & 0.1 & \\
\hline $20: 4 n-6$ & 3.3 & \pm & 0.8 & ab & 4.1 & \pm & 0.3 & & 2.9 & \pm & 0.2 & b & 2.7 & \pm & 0.3 & b & 2.4 & & 0.2 & \\
\hline $22: 5 n-6$ & 0.2 & \pm & 0.2 & D. & 0.1 & \pm & 0.0 & a & 0.5 & \pm & 0.0 & ab & 0.5 & \pm & 0.1 & a & 0.3 & & 0.1 & b \\
\hline Total n-6PUFA & 6.6 & \pm & 0.3 & & 6.6 & \pm & 0.8 & & 6.4 & \pm & 0.1 & & 6.7 & \pm & 0.3 & & 5.7 & & 0.6 & \\
\hline $18: 3 n-3$ & 0.5 & \pm & 0.0 & & 0.3 & $I$ & 0.0 & & 0.6 & \pm & 0.0 & & 0.5 & \pm & 0.1 & & 0.5 & & 0.0 & \\
\hline $18: 4 n-3$ & 0.2 & \pm & 0.0 & & 0.1 & \pm & 0.1 & & 0.2 & \pm & 0.0 & & 0.2 & \pm & 0.1 & & 0.2 & & 0.0 & \\
\hline $20: 3 n-3$ & 0.1 & \pm & 0.0 & & 0.1 & \pm & 0.1 & & 0.1 & \pm & 0.0 & & 0.1 & \pm & 0.1 & & 0.1 & & 0.1 & \\
\hline $20: 4 n-3$ & 0.4 & \pm & 0.1 & & 0.5 & \pm & 0.1 & & 0.5 & \pm & 0.1 & & 0.5 & \pm & 0.1 & & 0.5 & & 0.0 & \\
\hline $20: 5 n-3$ & 7.1 & \pm & 1.2 & & 7.0 & \pm & 1.1 & & 5.3 & \pm & 0.5 & & 5.2 & \pm & 0.5 & & 6.4 & & 0.6 & \\
\hline $22: 5 n-3$ & 1.5 & \pm & 0.1 & a & 1.5 & \pm & 0.1 & & 0.9 & \pm & 0.1 & & 1.2 & \pm & 0.2 & ab & 1.4 & \pm & 0.2 & a \\
\hline $22: 6 n-3$ & 36.2 & \pm & 1.6 & & 34.9 & \pm & 0.5 & & 42.3 & \pm & 0.9 & & 42.6 & \pm & 0.8 & a & 42.6 & & 0.9 & a \\
\hline Total n-3PUFA & 46.0 & \pm & 0.4 & c & 44.4 & \pm & 1.0 & & 50.0 & \pm & 0.3 & b & 50.3 & \pm & 0.2 & ab & 51.7 & \pm & 0.5 & a \\
\hline Total PUFA $^{1}$ & 52.7 & \pm & 0.2 & & 51.1 & \pm & 1.8 & & 56.5 & $I$ & 0.3 & & 57.1 & & 0.4 & & 57.6 & & 0.8 & \\
\hline$(n-3) /(n-6)$ & 7.0 & \pm & 0.3 & & 6.7 & \pm & 0.6 & & 7.8 & \pm & 0.2 & ab & 7.5 & \pm & 0.3 & b & 9.1 & \pm & 0.9 & a \\
\hline
\end{tabular}

${ }^{1}$ Includes C16PUFA. PUFA, polyunsaturated fatty acids. Data were subjected to one-way determined as described in the Materials and Methods section. Mean values in the same row with a different superscript letter are significantly different $(\mathrm{P}<0.05)$ as determined by Tukey's test. 
Table 6. Fatty acid composition of total polar lipid of livers from salmonids fed diets containing vegetable oils

\begin{tabular}{|c|c|c|c|c|c|c|c|c|c|c|c|c|c|c|c|c|c|c|c|c|}
\hline \multirow{2}{*}{$\begin{array}{l}\text { Fatty acid } \\
\text { Total saturates }\end{array}$} & \multicolumn{3}{|c|}{ C-charr } & & \multicolumn{3}{|c|}{ R-charr } & & \multicolumn{3}{|c|}{ Brown trout } & & \multicolumn{4}{|c|}{ S-salmon } & \multicolumn{4}{|c|}{ F1-salmon } \\
\hline & 25.4 & & 0.9 & a & 23.1 & \pm & 0.6 & b & 22.6 & & $=0.4$ & & 23.8 & \pm & 0.6 & ab & 23.9 & \pm & 0.4 & $\mathrm{ab}$ \\
\hline $16: 1 n-9$ & 0.1 & & 0.1 & & 0.2 & \pm & 0.2 & & 0.2 & & $=0.0$ & & 0.2 & \pm & 0.2 & & 0.4 & & 0.1 & \\
\hline $16: \ln -7$ & 1.0 & & 0.5 & & 1.0 & \pm & 0.5 & & 0.4 & \pm & $=0.0$ & & 0.6 & \pm & 0.4 & & 0.9 & \pm & 0.3 & \\
\hline $18: \ln -9$ & 14.5 & \pm & 1.6 & ab & 17.0 & \pm & 1.3 & a & 13.5 & \pm & $=0.6$ & b & 14.0 & \pm & 0.5 & b & 13.4 & \pm & 0.6 & b \\
\hline 18:1n-7 & 2.3 & \pm & 2.0 & & 1.3 & \pm & 1.2 & & 1.4 & \pm & $=0.1$ & & 0.7 & \pm & 0.6 & & 1.5 & \pm & 0.1 & \\
\hline $20: \ln -11 / 9$ & 2.6 & \pm & 1.2 & & 2.7 & \pm & 0.9 & & 1.4 & \pm & $=0.4$ & & 1.2 & \pm & 0.2 & & 1.0 & \pm & 0.2 & \\
\hline $20: 1 n-7$ & 0.2 & \pm & 0.0 & ab & 0.3 & \pm & 0.1 & a & 0.1 & \pm & $=0.0$ & b & 0.0 & \pm & 0.0 & b & 0.0 & \pm & 0.0 & b \\
\hline $22: 1 \mathrm{n}-11$ & 0.2 & \pm & 0.1 & & 0.3 & \pm & 0.0 & & 0.2 & \pm & $=0.0$ & & 0.3 & \pm & 0.1 & & 0.2 & \pm & 0.0 & \\
\hline $24: 1$ & 0.8 & & 0.2 & & 0.9 & \pm & 0.3 & & 0.8 & \pm & 0.2 & & 0.8 & \pm & 0.2 & & 1.3 & \pm & 0.2 & \\
\hline Total monoenes & 21.7 & \pm & 1.6 & a & 23.8 & \pm & 1.3 & a & 18.1 & \pm & $=0.2$ & b & 17.7 & \pm & 0.7 & b & 18.8 & \pm & 0.9 & b \\
\hline $18: 2 n-6$ & 2.1 & \pm & 0.6 & b & 2.3 & \pm & 0.5 & b & 6.3 & \pm & 0.6 & a & 7.7 & \pm & 0.4 & a & 6.7 & & 0.6 & a \\
\hline $18: 3 n-6$ & 0.1 & & 0.1 & & 0.2 & \pm & 0.1 & & 0.1 & \pm & 0.1 & & 0.3 & \pm & 0.2 & & 0.1 & & 0.1 & \\
\hline $20: 2 n-6$ & 0.5 & \pm & 0.2 & ab & 0.2 & \pm & 0.0 & b & 1.1 & \pm & $=0.5$ & ab & 1.4 & \pm & 0.6 & a & 0.9 & \pm & 0.3 & ab \\
\hline $20: 3 n-6$ & 0.2 & \pm & 0.0 & b & 0.2 & \pm & 0.0 & b & 1.9 & \pm & 0.1 & a & 2.2 & \pm & 0.7 & a & 2.0 & \pm & 1.0 & a \\
\hline $20: 4 n-6$ & 4.0 & \pm & 0.3 & ab & 4.6 & \pm & 0.3 & a & 2.7 & \pm & $=0.3$ & b & 2.2 & \pm & 0.3 & b & 2.2 & \pm & 0.2 & b \\
\hline $22: 5 n-6$ & 0.2 & & 0.1 & & 0.3 & \pm & 0.0 & & 0.3 & \pm & $=0.0$ & & 0.3 & \pm & 0.0 & & 0.3 & \pm & 0.0 & \\
\hline Total n-6PUFA & 7.1 & & 0.8 & b & 7.8 & \pm & 0.6 & $\mathrm{~b}$ & 12.4 & \pm & $=0.5$ & a & 14.1 & \pm & 1.5 & a & 12.2 & \pm & 2.0 & a \\
\hline $18: 3 n-3$ & 0.4 & & 0.1 & b & 0.4 & \pm & 0.1 & $\mathrm{~b}$ & 3.8 & \pm & 0.4 & & 4.5 & \pm & 0.4 & a & 3.8 & \pm & 0.7 & a \\
\hline $18: 4 n-3$ & 0.2 & & 0.1 & & 0.2 & \pm & 0.1 & & 0.4 & \pm & $=0.2$ & & 0.7 & \pm & 0.4 & & 0.6 & & 0.2 & \\
\hline $20: 3 n-3$ & 0.1 & & 0.1 & ab & 0.0 & \pm & 0.0 & $\mathrm{~b}$ & 0.6 & \pm & $=0.2$ & a & 0.6 & \pm & 0.1 & a & 0.4 & \pm & 0.1 & a \\
\hline $20: 4 n-3$ & 0.4 & & 0.0 & b & 0.5 & \pm & 0.1 & ab & 1.2 & \pm & $=0.1$ & a & 1.2 & \pm & 0.4 & a & 1.1 & & 0.4 & ab \\
\hline $20: 5 n-3$ & 6.7 & & 0.3 & ab & 7.1 & \pm & 0.4 & a & 5.6 & \pm & $=0.6$ & bc & 4.5 & \pm & 1.3 & & 5.1 & \pm & 1.0 & bc \\
\hline $22: 5 n-3$ & 1.1 & \pm & 0.1 & & 1.7 & \pm & 0.1 & a & 1.3 & \pm & 0.1 & hc & 1.4 & \pm & 0.1 & & 1.4 & & 0.1 & hc \\
\hline $22: 6 n-3$ & 36.8 & \pm & 0.8 & & 35.2 & \pm & 0.6 & ah & 34.0 & \pm & $=0.5$ & & 31.3 & \pm & 0.3 & c & 32.6 & \pm & 1.9 & he \\
\hline Total n-3PUFA & 45.7 & & 0.5 & & 45.1 & \pm & 1.1 & & 46.9 & \pm & $=0.5$ & & 44.2 & \pm & 1.4 & & 45.0 & \pm & 2.8 & \\
\hline Total PUFA $^{1}$ & 52.9 & & 0.7 & & 53.1 & \pm & 0.8 & & 59.3 & & 0.3 & & 58.5 & \pm & 0.1 & & 57.3 & \pm & 1.0 & \\
\hline$(n-3) /(n-6)$ & 6.4 & & 0.7 & a & 5.8 & \pm & 0.5 & a & 3.8 & \pm & $=0.2$ & & 3.1 & \pm & 0.5 & & 3.7 & \pm & 0.8 & b \\
\hline
\end{tabular}

${ }^{1}$ Includes C16 PUFA. PUFA, polyunsaturated fatty acids. Data were subjected to one-way ANOVA as described in the Materials and Methods section. Mean values in the same row with a different superscript letter are significantly different $(\mathrm{P}<0.05)$ as determined by Tukey's test. 
Table 7. Results of two-way analysis of variance (ANOVA) on data in Tables 5 and 6 for the significance of differences due to species and diet on selected relevant fatty acids.

\begin{tabular}{|c|c|c|c|c|}
\hline Fatty acid & Treatment & $\mathrm{P}$ & F value & significance \\
\hline \multirow[t]{3}{*}{$18: 1 n-9$} & species & $<0.0001$ & 36.24 & $*$ \\
\hline & diet & $<0.0001$ & 117.14 & * \\
\hline & interaction & 0.0044 & 5.31 & * \\
\hline \multirow[t]{3}{*}{$18: 2 n-6$} & species & $<0.0001$ & 72.30 & $*$ \\
\hline & diet & $<0.0001$ & 397.56 & $*$ \\
\hline & interaction & $<0.0001$ & 41.23 & $*$ \\
\hline \multirow[t]{3}{*}{$20: 4 n-6$} & species & $<0.0001$ & 34.81 & * \\
\hline & diet & 0.6535 & 0.21 & ns \\
\hline & interaction & 0.0416 & 3.03 & $*$ \\
\hline \multirow[t]{3}{*}{$18: 3 n-3$} & species & $<0.0001$ & 76.46 & * \\
\hline & diet & $<0.0001$ & 389.12 & $*$ \\
\hline & interaction & $<0.0001$ & 66.62 & $*$ \\
\hline \multirow[t]{3}{*}{$20: 5 n-3$} & species & 0.0005 & 7.93 & $*$ \\
\hline & diet & 0.1993 & 1.76 & ns \\
\hline & interaction & 0.4808 & 0.9 & ns \\
\hline \multirow[t]{3}{*}{$22: 6 n-3$} & species & 0.0004 & 8.42 & $*$ \\
\hline & diet & $<0.0001$ & 246.61 & $*$ \\
\hline & interaction & $<0.0001$ & 49.51 & * \\
\hline & & & & \\
\hline
\end{tabular}

